
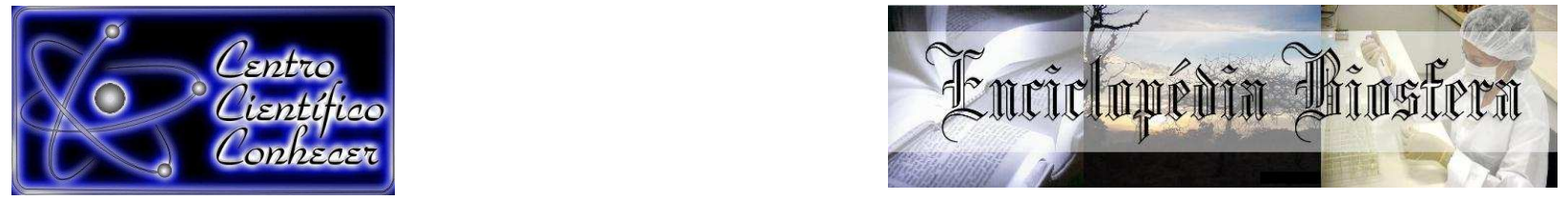

\title{
METODOLOGIAS DE AVALIAÇÃO DE IMPACTOS AMBIENTAIS DA APP, RANCHO TUTTY FALCÃO GURUPI-TO
}

Patrícia Aparecida de Souza ${ }^{1}$, Ana Paula Alves dos Santos Glória², Douglas Santos Gonçalves $^{3}$, André Ferreira dos Santos ${ }^{1}$, Priscila Bezerra de Souza ${ }^{1}$

1 Professor (a) Dr.(a) do departamento de Engenharia Florestal da Universidade Federal do Tocantins, Gurupi - Brasil (patriciaapsouza@mail.uft.edu.br)

2 Engenheira Florestal da Universidade Federal do Tocantins, Gurupi - Brasil 3 Mestre em Ciências Florestais e Ambientais da Universidade Federal do Tocantins, Gurupi - Brasil

Recebido em: 03/10/2016 - Aprovado em: 21/11/2016 - Publicado em: 05/12/2016 DOI: 10.18677/EnciBio_2016B_066

\begin{abstract}
RESUMO
O presente estudo utilizou metodologias de avaliação de impactos ambientais para relatar os impactos ocorridos à margem direita da APP Rancho Tutty Falcão, Gurupi - TO. Sendo desenvolvido em 400 metros da margem da represa, área que está localizada dentro da propriedade. Para realização do diagnóstico foram utilizadas as metodologias do "Check-list", rede de interação e matriz de interação. A análise temporal foi feita com o geoprocessamento das imagens dos anos de 1990, 1996, 2006 e 2016 através do ArcGIS 9.3. Os impactos mais relevantes visualizados no local durante a visita técnica na propriedade foram a remoção da vegetação nativa, exposição do solo, assoreamento, introdução de espécies exóticas e excesso de vegetação aquática. Através da matriz de interação constatou-se que o meio mais impactado foi o meio físico, mais precisamente a água, com a análise temporal foi possível ver que área vem sendo degradada ao longo do tempo e que a vegetação retirada para formação da represa não foi recomposta. Diversos impactos foram vistos na área necessitando de recuperação, sendo necessária a realização de um PRAD.
\end{abstract}

PALAVRAS-CHAVE: Diagnóstico ambiental, qualitative analysis, temporal analysis

\section{IMPACT ASSESSMENT METHODOLOGIES OF ENVIRONMENTAL APP RANCHO TUTTY FALCÃO GURUPI-TO.}

\begin{abstract}
The study used methods of environmental impact assessment report to the impacts occurring on the right bank of APP Ranch Tutty Falcão, Gurupi - TO. It is developed at 400 meters from the shore of the dam, the area that is located within the boundaries of the property. For making the diagnosis the methodologies of "check list", network interaction and interaction matrix. The temporal analysis was performed with geoprocessing images of 1990, 1996, 2006 and 2016 through ArcGIS 9.3. The most significant impacts observed in the area during the technical visit on the property were the removal of native vegetation, soil exposure, silting, introduction of exotic species and excess aquatic vegetation. Through interaction matrix was found 2016
\end{abstract}


that the most affected medium is the physical medium, more particularly water, with a temporal analysis it was possible to see that the area has been degraded over time and that the vegetation removed to dam formation was not recomposed. Several impacts were seen in the area in need of recovery, requiring the application of a PRAD.

KEYWORDS: Environmental diagnosis, permanent preservation area, network interaction.

\section{INTRODUÇÃO}

O território brasileiro foi e tem sido ocupado de forma desordenada o que provocou e ainda provoca a devastação dos recursos naturais, em especial das florestas, que ao longo da história vem sendo fragmentadas e ocupadas por culturas agrícolas, pastagens e cidades, ocupações essas que atingiram as matas ciliares (MARTINS, 2013).

As matas ciliares podem ser entendidas como sistemas florestais encontrados naturalmente as margens de rios, riachos, lagos, represas e nascentes, e auxiliam na redução do assoreamento e da degradação do meio ambiente e transformação da diversidade ambiental (CASTRO et al., 2013).

Muitos problemas ambientais são gerados a partir da degradação das matas ciliares como a escassez e a contaminação da água, sendo que as mesmas funcionam como filtro, evitando que defensivos agrícolas, poluentes e sedimentos cheguem aos cursos d'água, que consequentemente afetariam a fauna aquática e a população humana (MARTINS, 2014).

A influência humana sobre esse tipo de vegetação, além de ser proibida pelo Código Florestal vigente, traz uma série de danos ambientais e diante de sua importância para a qualidade de vida do homem e dos ecossistemas, a manutenção e a recuperação das matas ciliares se faz necessária (FERREIRA \& DIAS, 2004). Para que as matas ciliares sejam recuperadas é necessário que se faça uma avaliação das condições ambientais destas áreas. E esta avaliação pode ser feita por meio de um diagnóstico ambiental (GONÇALVES et al., 2016).

O diagnóstico ambiental é utilizado na identificação, caracterização e mapeamento dos recursos naturais, bem como das atividades antrópicas que incidem sobre uma determinada região, para que possam ser identificados e avaliados os possíveis impactos. Definido também como uma técnica de inventário, que analisa e interpreta informações relacionadas aos componentes naturais e ambientais para determinar a situação atual dos mesmos (FERREIRA et al., 2015).

Para a execução do diagnóstico ambiental podem ser utilizadas as metodologias do "Check list", a matriz de interação e a rede de interação, que são métodos bem sucedidos na identificação de impactos ambientais.

No "Check list", os possíveis fatores ambientais que podem provocar alteração no ambiente são listados, enquanto que a matriz de interação inicialmente surgiu como alternativa para suprir as deficiências do "Check list". Diante do exposto, utilizaram-se metodologias de avaliação de impactos ambientais para relatar os impactos ocorridos à margem direita da APP Rancho Tutty Falcão, Gurupi - TO.

\section{MATERIAL E MÉTODOS}

O presente estudo foi conduzido na propriedade denominada Rancho Tutty Falcão que possui uma área de 59,71 hectares, localizada na zona rural do 
Município de Gurupi, Estado do Tocantins, sob as coordenadas geográficas $11^{\circ} 46^{\prime} 49,43^{\prime \prime} S$ e $49^{\circ} 02^{\prime} 30,11^{\prime \prime W}$. O clima da região s egundo Köppen é do tipo AW, definido como tropical úmido com estação chuvosa no verão e seca no inverno. As temperaturas médias ao longo do ano variam entre $22^{\circ} \mathrm{C}$ e $28^{\circ} \mathrm{C}$ e a precipitação média anual varia entre $1.500 \mathrm{~mm}$ a $1.600 \mathrm{~mm}$.

A avaliação foi realizada em 400 metros, na margem da represa (Figura 1), área que está localizada dentro da propriedade. A represa foi construída no início da década de 1990 com o barramento do córrego Bananal e inundou uma área de 194 hectares e acumulou um volume de $5.518 .488 \mathrm{~m}^{3}$ e é usada na captação de água para abastecer a população da cidade de Gurupi, Tocantins (ODEBRECHT AMBIENAL/ SANEATINS, 2014).

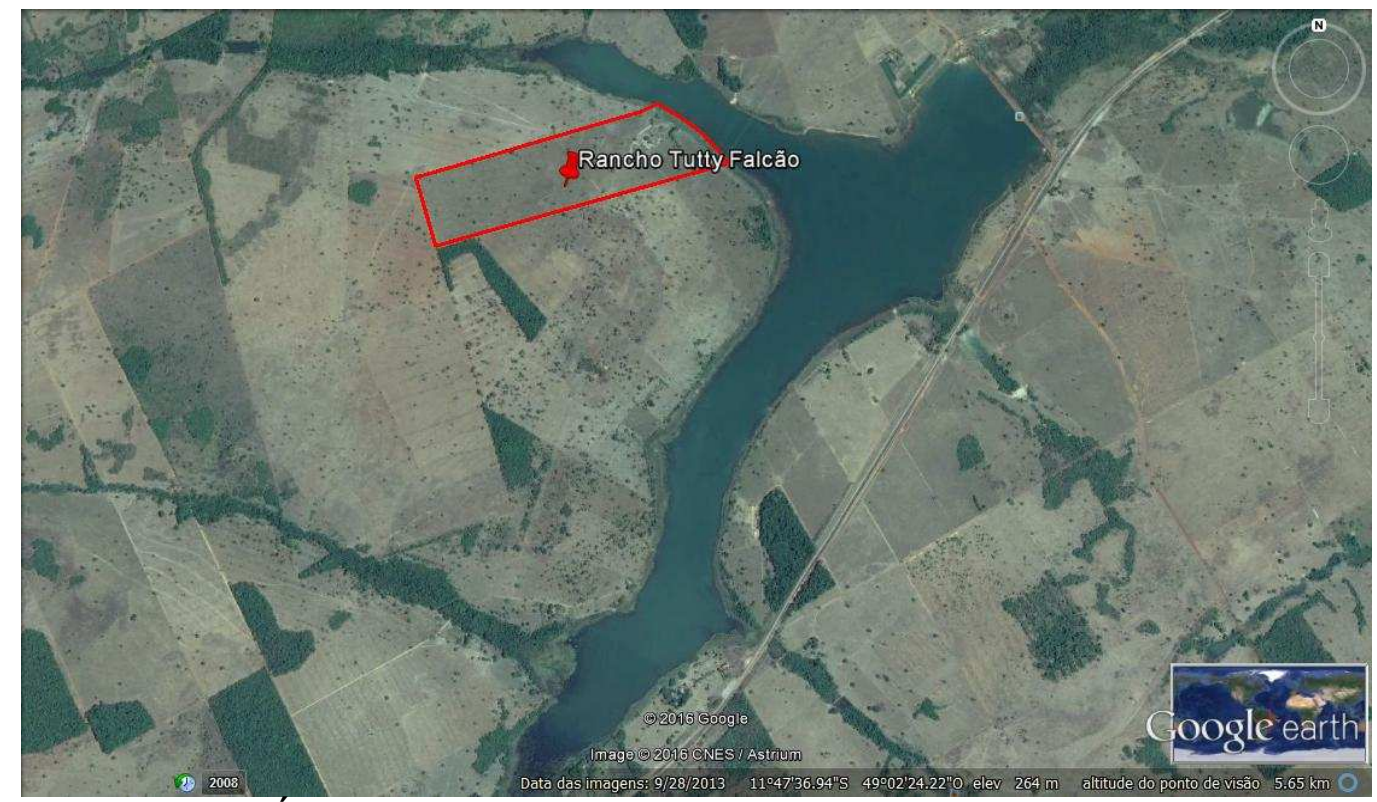

FIGURA 1. Área de estudo, destacando os $400 \mathrm{~m}$, na APP, Rancho Tutty Falcão, Gurupi - TO. Fonte: Earth Explorer (2016).

Os dados foram coletados no mês maio de 2016, em visita técnica ao local, com auxílio de uma câmera digital para a captura de imagens e material para anotação. Após a visualização dos principais impactos presente no local, foi elaborado "Check-list" descritivo, de acordo com a metodologia utilizada por SÁNCHEZ, (2006).

A elaboração da rede de interação teve como base o "Check-list", tendo como forma de apresentação o fluxograma e partiu de um impacto principal, onde outros sucessivos foram organizados em demais ordens. A avaliação quantitativa foi realizada com a adaptação de matriz de interação derivada de LEOPOLD et al. (1971) e adaptada por TOMMASI (1993), onde foram analisadas a magnitude e a importância dos impactos, que foram relacionados em um quadro e enumerados horizontal e verticalmente, com valores que variam de 1 a 10 .

A análise temporal foi elaborada com imagens dos anos 1990, 1996, 2006 e 2016, sendo estas referentes ao mês de junho dos respectivos anos. A imagem de 1990 foi obtida do satélite Landsat 5 (Bandas 3, 4 e 5) as dos anos de 1996 e 2006 do Landsat 7 (Bandas 3, 4 e 5) no catálogo de imagens do Instituto Nacional de Pesquisas Espaciais (INPE, 2016) e a do ano de 2016 foi obtida do satélite Landsat 8 (Bandas 4, 5 e 6) no site Earth Explorer (EARTH EXPLORE, 2016). 
Após a aquisição das imagens as mesmas foram processadas no programa ArcGIS 9.3, onde foram geoprocessadas para que suas coordenadas correspondessem com a realidade. As classes (água, solo exposto, pastagem e vegetação) foram quantificadas tendo como base a geometria dos polígonos que formavam cada uma das classes, esse valor foi obtido em metros e então divido por 10000 para que pudesse ser obtido em hectare. Posteriormente a realização e conclusão destes processos, foram propostas medidas de mitigação para a área em estudo.

\section{RESULTADOS E DISCUSSÃO}

Utilizando-se o diagnóstico ambiental conduzido às margens da APP Rancho Tutty Falcão, observou-se através da metodologia do "Check-list" que a principal ação impactante ocorrente na área foi a remoção da vegetação nativa e os impactos ambientais decorrentes dessa ação foram, a exposição do solo, assoreamento, introdução de espécies exóticas e vegetação aquática em excesso.

A remoção da vegetação nativa ocorreu para dar lugar a represa (Figura 2), de acordo com OLIVEIRA et al. (2015), esse fato, influencia negativamente o solo, a água e à fauna, pois expõe e fragiliza o solo, afeta a proteção natural que é fornecida pela vegetação, causando a desestruturação do solo e diminuição da serapilheira.

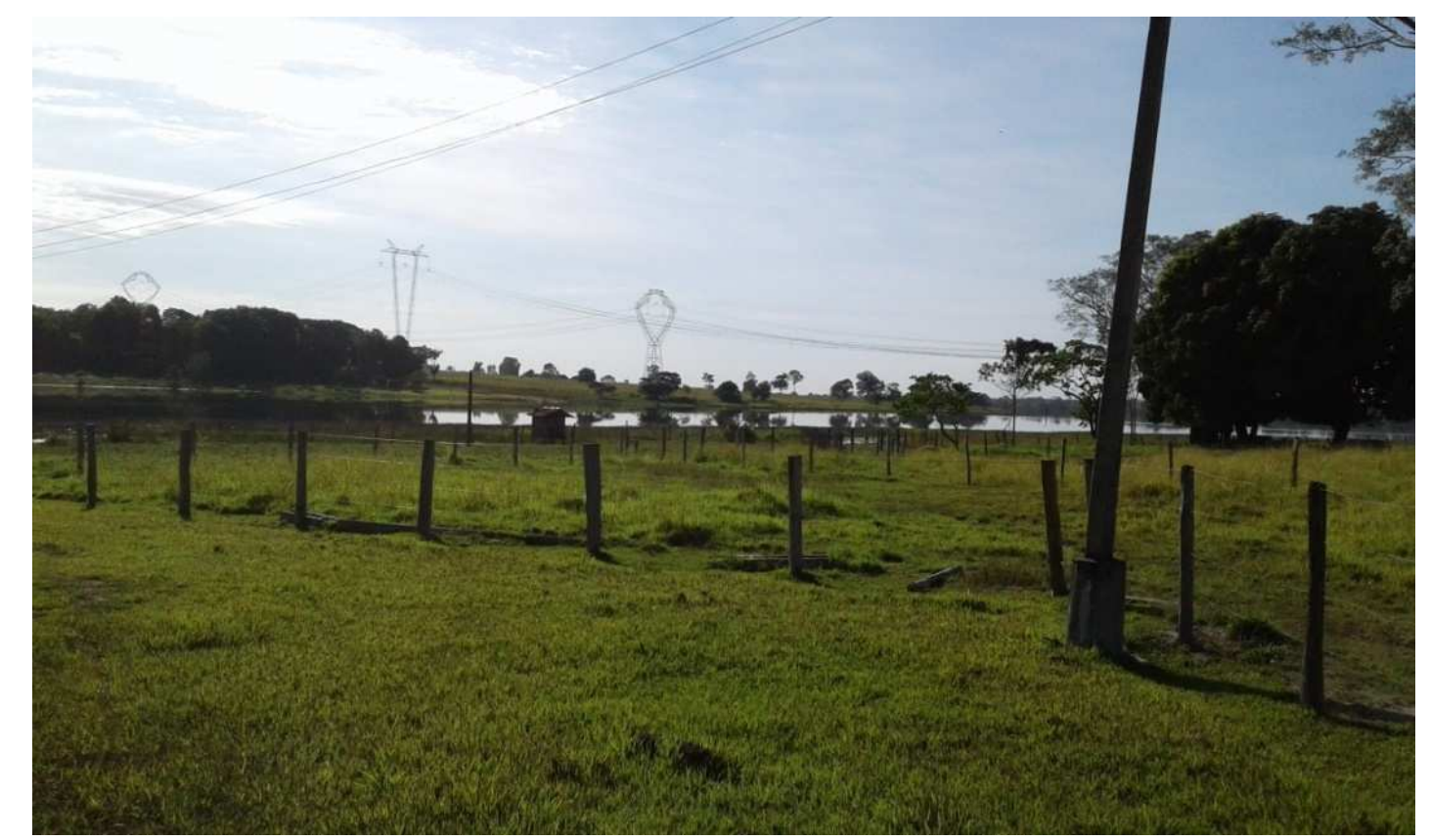

FIGURA 2. Falta de vegetação nativa, na APP, Rancho Tutty Falcão, Gurupi - TO. Fonte: Autores (2016).

O impacto ambiental exposição do solo foi observado em alguns pontos da área de estudo. Segundo GIUNTI et al. (2012) Os impactos sofridos no solo atuam de maneira negativa em todas as suas características (físicas-químicas e biológicas). Com a remoção da vegetação e da matéria orgânica, que funcionam como proteção, as áreas mais frágeis do solo são expostas e como consequência toda dinâmica acaba sendo alterada, com perda de qualidade e perda física das partículas do solo, causando erosão. 
O assoreamento observado na área de estudo, foi constatado pelo acumulo de partículas de solo à margem da represa. Uma das possíveis causas desse impacto além da exposição do solo deve ser o fluxo de seres humanos, animais e veículos na área, que também é utilizada para lazer, embora a área esteja em parte coberta por gramíneas, essa ação não está sendo suficiente para conter as partículas de solo e evitar que cheguem ao corpo hídrico (Figura 3).

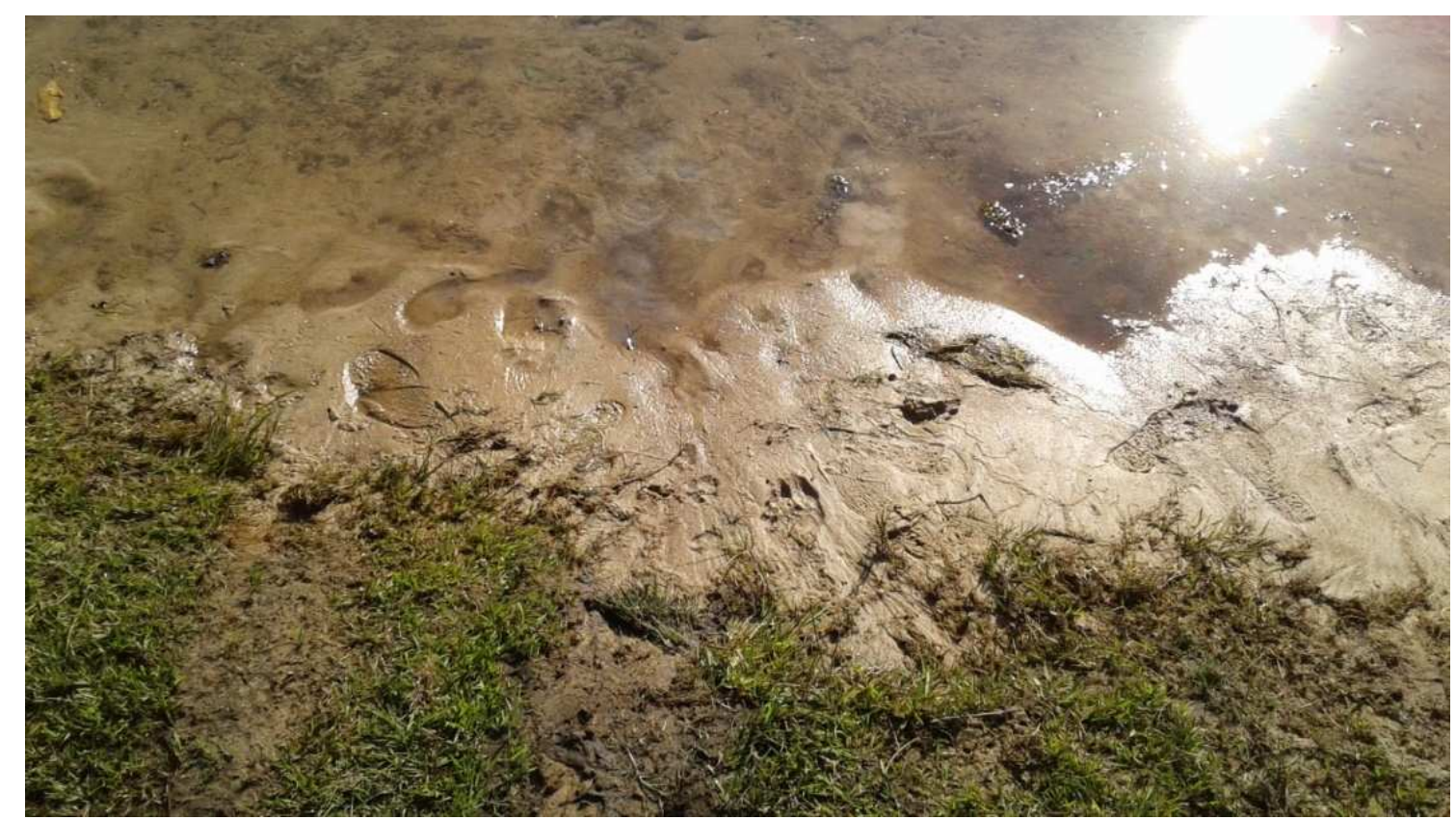

FIGURA 3. Assoreamento observado à margem direita da represa, na APP, Rancho Tutty Falcão, Gurupi - TO. Fonte: Autores (2016).

CASTRO et al. (2013) relatam que a principal causa do assoreamento dos corpos hídricos é a remoção da vegetação nativa que atua na proteção solo e da água, e que com a retirada fica sem proteção e sujeitas ao assoreamento. De acordo com os mesmos autores o assoreamento reduz o volume de água, tornandoa turva e impossibilita a entrada de luz dificultando a fotossíntese e impedindo a renovação do oxigênio para algas e peixes, conduzindo rios e lagos ao desaparecimento.

A introdução de espécies exóticas ocorreu para formação de pastagem. $O$ surgimento de espécies consideradas exóticas, afeta diretamente a germinação das espécies, pois estas competem entre si por nutriente, luz e água, além de ser um dos principais fatores que podem impedir a regeneração natural das espécies nativas (MARTINS, 2015). No local de desenvolvimento do estudo, observou-se vegetação aquática presente em diversos pontos da represa, tendo como uma das principais causas o aporte de nutrientes do solo e também o carreamento das fezes dos animais que se alimentam no local.

De acordo com BARRETO et al., (2013) as plantas aquáticas surgem a partir do enriquecimento do meio aquático provocado pelo aporte de nutrientes, principalmente nitrogênio e fosforo, que aceleram o processo de eutrofização, que é caracterizada pelo aumento excessivo de nutrientes na água, e que pode ser causada por drenagem de fertilizantes agrícolas, águas pluviais de cidades, detergentes, resíduos de minas, drenagem de dejetos humanos entre outros fatores. 
A rede de interação está organizada na ordem dos impactos ambientais incitados pela ação impactante retirada da vegetação nativa e esta ação gerou os impactos de demais ordens (Figura 4). Segundo TOMMASI (1993) a rede de interação é importante, pois através dela pode-se encontrar os impactos de todas as ordens.

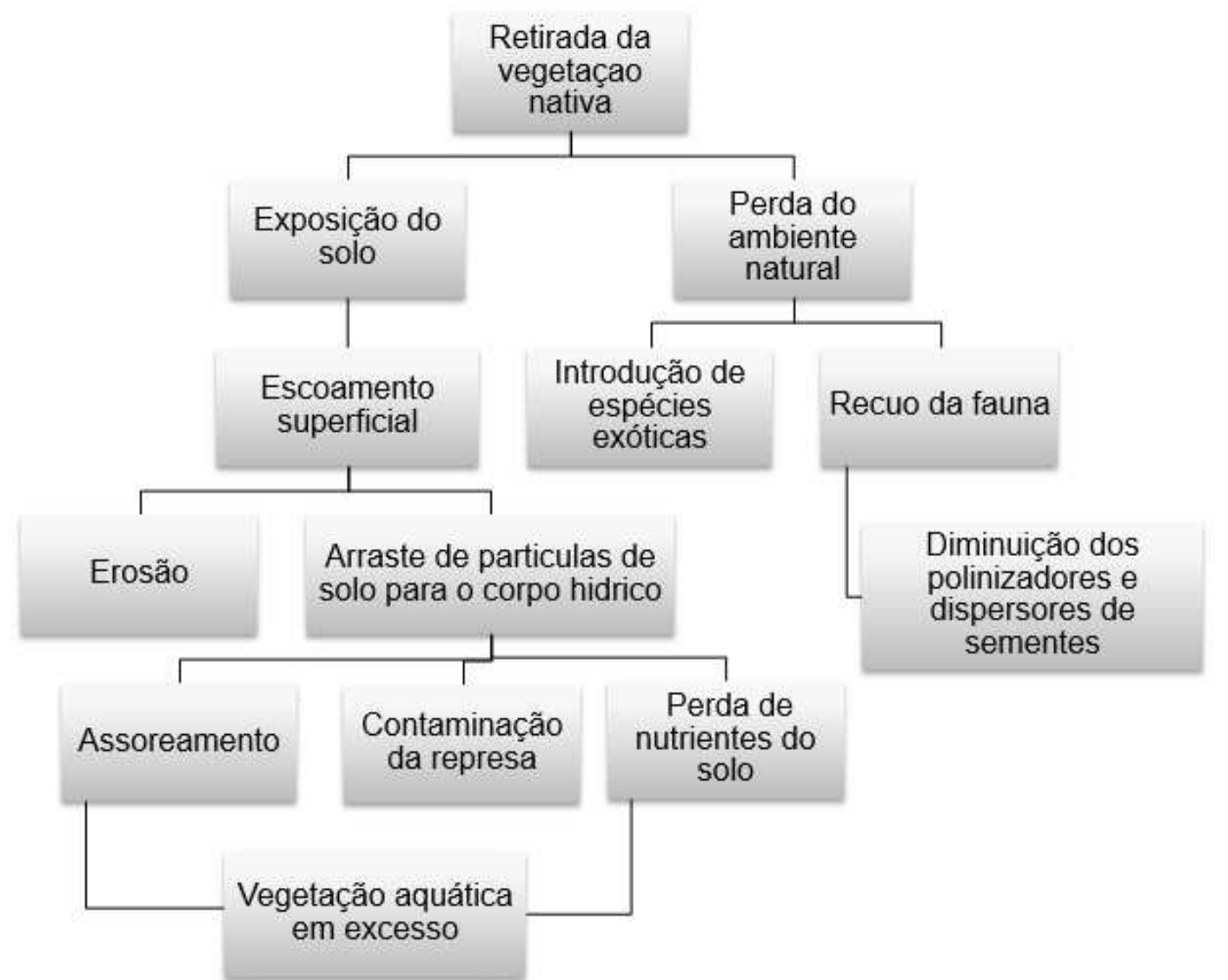

FIGURA 4. Rede de interação da APP, Rancho Tutty Falcão, Gurupi - TO. Fonte: Autores (2016).

A remoção da vegetação nativa provocou a exposição do solo, que ocasionou o escoamento superficial, que por sua vez resultou na erosão e arraste de partículas do solo para o corpo hídrico, provocando o assoreamento da represa, a perda de nutrientes do solo e contaminação da represa, que contribuíram para houvesse o excesso de vegetação aquática.

A perda do ambiente natural motivado pela remoção da vegetação nativa possibilitou que espécies exóticas fossem introduzidas na área provocando o recuo da fauna e consequentemente a diminuição da população de animais polinizadores e dispersores de sementes. A elaboração da rede de interação possibilitou que os efeitos provocados pela remoção da vegetação nativa nos meios físico, biótico e antrópico, fossem mais facilmente visualizados.

A rede de interação foi utilizada por OLIVEIRA et al., (2015), na elaboração de proposta de recuperação para a nascente do córrego Mutuca no município de Gurupi -Tocantins. A quantificação das ações impactantes e dos impactos ambientais foi feita a partir da Matriz de LEOPOLD et al. (1971), adaptada por TOMMASI (1993) (Figura 5). 


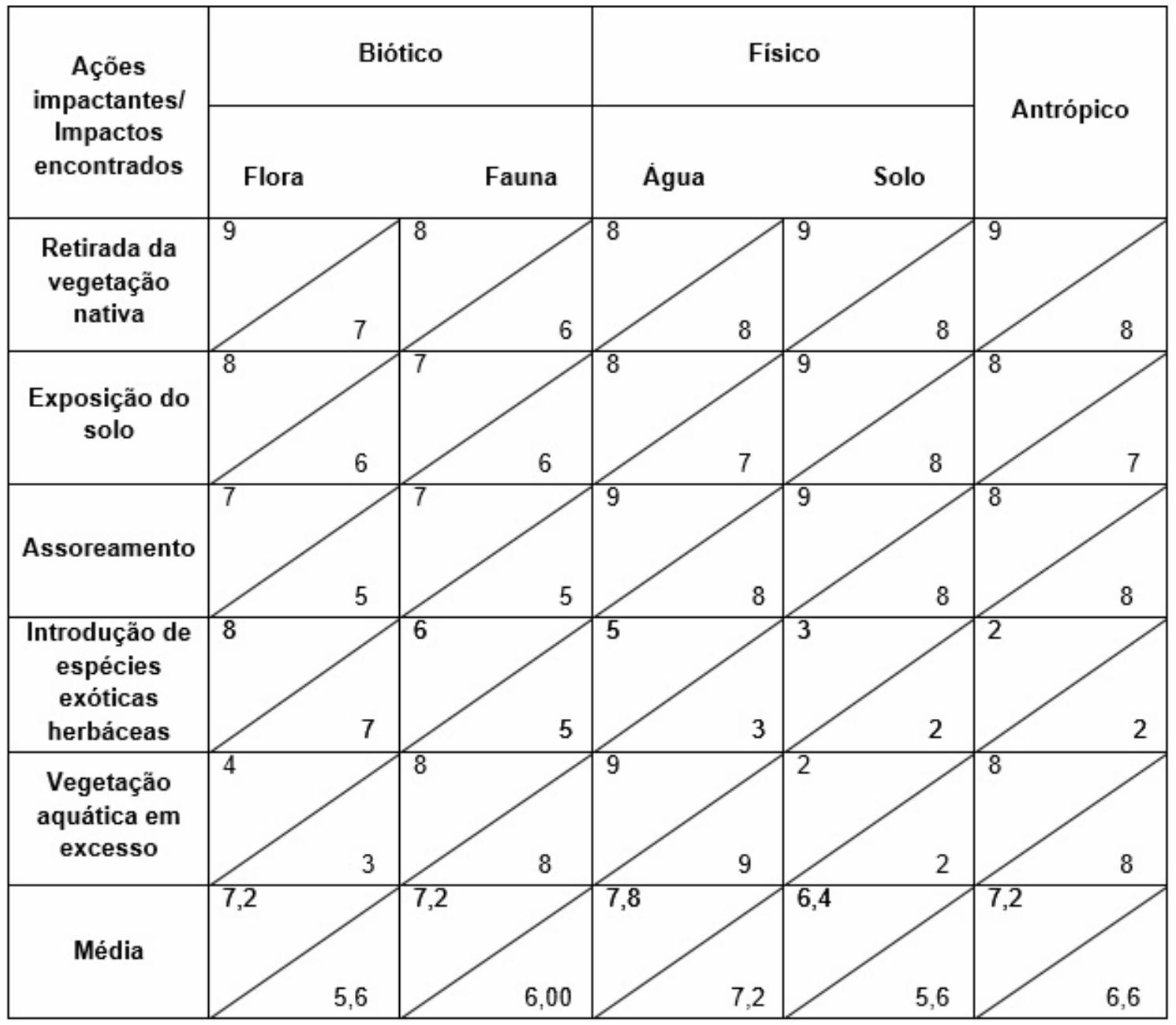

FIGURA 5. Matriz de inteiração da ação impactante e dos impactos ambientais encontrados na APP, Racho Tutty Falcão, Gurupi - TO. Fonte: Autores (2016).

Os impactos ambientais exibem duas propriedades principais: a magnitude e a importância. A magnitude é definida como a grandeza, em escala espacial e temporal, de um impacto e a importância é caracterizada como intensidade do efeito conexo com um determinado fator ambiental, com outros impactos ou com algumas características (LEOPOLD et al., 1971).

Com relação à matriz de interação os maiores valores foram quantificados no meio físico, mais precisamente na água com 7,8 de magnitude e 7,2 de importância, essa média relativamente alta atribuída para magnitude, mostra a consequência daquele tipo de ação sobre o atributo ambiental. Esses valores encontrados para o meio físico, água podem ter ocorrido, devido os impactos ambientais como assoreamento provocado pela exposição do solo e excesso de vegetação aquática afetar diretamente esse ambiente (Figura 5).

O meio com menor valor quantificado foi o solo, com 6,4 de magnitude e 5,6 de importância, tais valores foram atribuídos pelo fato do mesmo, estar parcialmente exposto, levando em consideração que grande parte se encontra protegido pela pastagem introduzindo no local (Figura 5). GONÇALVES et al., (2016), fizeram uso da matriz de interação para realizar um diagnóstico ambiental na APP de um fazenda no Município de Cariri do Tocantins - TO. 


\section{Análise Temporal}

O uso de sensoriamento remoto possibilita uma melhor compreensão do contexto temporal, no monitoramento e planejamento do meio físico, pois permite uma avaliação da exposição das áreas de preservação e de vegetação natural (NERY et al., 2014). A análise temporal da área de estudo indicou que no ano de 1990, antes da criação da represa, a maior parte da APP Rancho Tutty Falcão estava com solo desprotegido ocupando $48,99 \%$ da propriedade, enquanto a pastagem ocupava $42,26 \%$ e a vegetação $8,73 \%$, dentro dos 400 metros onde 0 estudo foi desenvolvido (Figura 6).
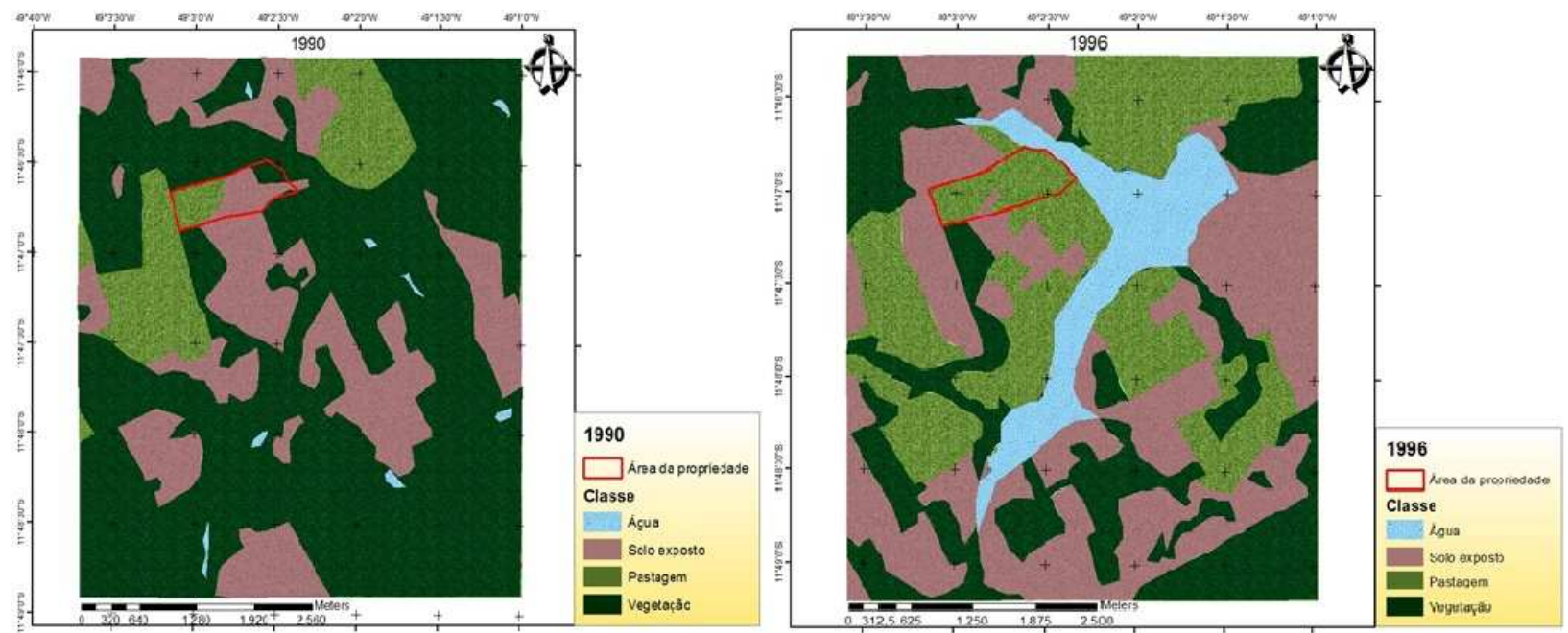

FIGURA 6. Análise temporal da área estudo, anos 1990 e 1996, dentro dos $400 \mathrm{~m}$ onde foi conduzido o trabalho, APP Racho Tutty Falcão, Gurupi - TO. Fonte: Arquivo dos autores (2016).

No ano de 1996, observou-se que a represa já havia sido construída e nos 400 metros onde foi realizado o estudo, a presença da pastagem ocupava $91 \%$ da área e a vegetação nativa apenas $0,13 \%$, pois esta provavelmente foi retirada para formação da represa, não sendo recomposta (Figura 6).

Segundo MARTINS (2014) a recomposição das matas ciliares se faz necessária por serem de grande importância para o desenvolvimento sustentável de todo o país, por cumprirem o papel de proteger as margens dos corpos d'água, evitando o assoreamento, e promovendo a regularização da vazão dos rios e córregos, além de servir como abrigo e alimentação para a fauna local.

Em 2006, a quantidade de vegetação na APP Rancho Tutty Falcão teve um acréscimo se comparara ao ano de 1996 e ocupava $26,55 \%$ da área, indicando que nesse período, provavelmente estava ocorrendo regeneração natural da vegetação nativa, porém o solo exposto ocupava $68,21 \%$ da área sem nenhum tipo de cobertura (Figura 7). 


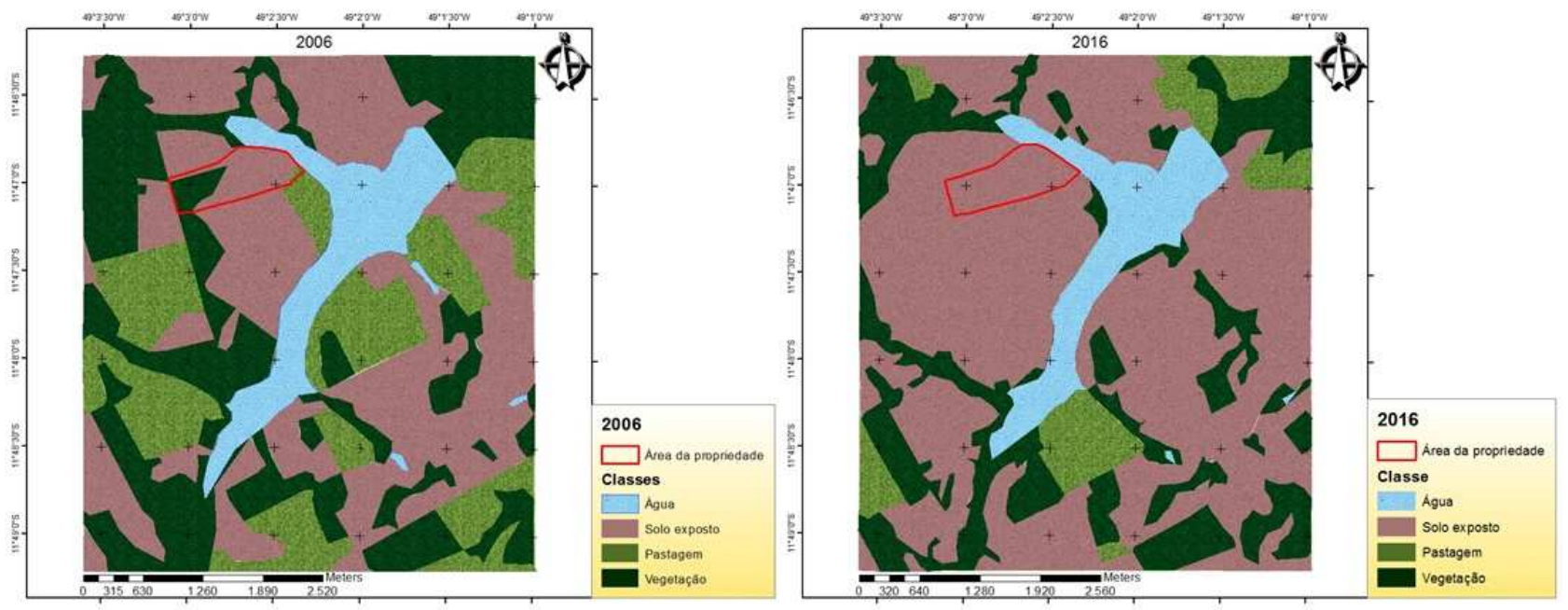

FIGURA 7. Análise temporal da área estudo, anos 2006 e 2016, dentro dos $400 \mathrm{~m}$ onde foi conduzido o trabalho, APP Racho Tutty Falcão, Gurupi - TO. Fonte: Arquivo dos autores (2016).

No último ano em análise, 2016, a área de estudo APP Rancho Tutty Falcão, encontrava-se com $95,84 \%$ de solo exposto, com $1,85 \%$ de pastagem e o valor irrisório de $0,1 \%$ com vegetação, evidenciado grande degradação no local de desenvolvimento do estudo (Figura 7).

Através da observação das imagens da análise temporal da área de estudo, pode-se confirmar o que foi observado em campo por meio do diagnóstico ambiental, a retirada da vegetação nativa e a exposição do solo, que vem ocorrendo há bastante tempo, desencadeando assim outros impactos, como o assoreamento e o excesso de vegetação aquática. Observou-se ainda através das imagens no decorrer dos anos, que esses impactos ambientais vão além dos limites da propriedade, se estendendo por grande parte da margem da represa (Figuras 6 e 7).

Neste contexto, cabe ressaltar que o Código Florestal Brasileiro em vigência (Lei $\left.n^{\circ} 12.651 / 2012\right)$, relata que a implantação de reservatório d'água artificial destinado ao abastecimento público, deve ter a faixa de proteção estabelecida no licenciamento ambiental (BRASIL, 2012). A Lei Estadual no 1.939, de 24 de junho de 2008 estabelece que as APP's as margens de corpos hídricos artificiais devem ter uma faixa mínima de 30 metros (TOCANTINS, 2008). Desta maneira área de APP Rancho Tutty Falcão, encontra-se em desacordo com estas leis, mostrando a necessidade de intervenção antrópica e execução de medidas mitigatórias para conter o avanço dos impactos e posterior elaboração de um Plano de Recuperação de Áreas Degradadas (PRAD) no local.

As medidas mitigatórias propostas são o isolamento da área, que deve ser cercada para evitar a entrada de pessoas e animais e controle da vegetação exótica. $\mathrm{Na}$ execução do PRAD, recomenda-se a indução e condução da regeneração natural onde ainda for possível e nos locais onde não for possível a regeneração natural, devem-se plantar espécies florestais nativas e/ou frutíferas nativas da região.

\section{CONCLUSÕES}

- A área possui um grande número de impactos ambientais, sendo a ação impactante retirada da vegetação nativa, desencadeadora dos impactos ambientais: exposição do solo, assoreamento, introdução de espécies exóticas e excesso de vegetação aquática. 
- O meio físico solo foi o mais afetado, mais precisamente a água.

- As imagens da análise temporal mostraram que após a construção da represa na década de 1990 a degradação da área teve grande aumento nos últimos 26 anos.

- As medidas de mitigação indicadas são o isolamento da área, que deve ser cercada para evitar a entrada de pessoas e animais e controle da vegetação exótica. Na execução do PRAD, recomenda-se a indução e condução da regeneração natural onde ainda for possível e nos locais onde não for possível a regeneração natural, devem-se plantar espécies florestais nativas e/ou frutíferas nativas da região.

\section{REFERÊNCIAS}

BRASIL - CÓDIGO FLORESTAL BRASILEIRO - Lei $\mathbf{n}^{\circ} 12.651$ de maio de 2012. Disponível em: <http://www.planalto.gov.br/ccivil_03/_ato2011 2014/2012/lei//12651.htm>. Acesso em: 13 junho 2016.

BARRETO, L. V.; BARROS, F. M.; BONOMO, P.; ROCHA, F. A.; AMORIM, J. da. S. Eutrofização em rios brasileiros. Enciclopédia Biosfera. V 9, n. 16, p. 2166, 2013.

CASTRO M. N.; CASTRO P.M.; SOUZA P.C. A importância da mata ciliar no contexto da conservação do solo. Revista Eletrônica de Educação da Faculdade Araguaia, v. 4, p. 230-241. 2013.

EARTH EXPLORER. 2016. Disponível em: <http://earthexplorer.usgs.gov/> Acesso em: 26 de maio de 2016.

FERREIRA, D. A. C.; DIAS, H. C. T. Situação atual da mata ciliar do ribeirão São Bartolomeu em Viçosa, MG. Revista Árvore, n. 4, p.617-623, 2004. Disponivel em: < http://dx.doi.org/10.1590/S0100-67622004000400016>. doi: 10.1590/S010067622004000400016.

FERREIRA, R. Q. de S.; Batista, E. M. C.; Souza, P.A. de.; Souza, P. B.; Santos, A. F. Diagnóstico ambiental do córrego Mutuca, Gurupi - TO. Revista Verde de agroecologia e Desenvolvimento Sustentável, v.10, n. 4, p. 08-12, 2015. Disponível em < http://dx.doi.org/10.18378/rvads.v10i4.3146> doi: 10.18378/rvads.v10i4.3146.

GIUNTI, O. D.; DE SÁ, E. B. R.; DE OLIVEIRA, T. C.; SILVA, A. V. Análise e Diagnóstico Ambiental: Adequações ao Novo Código Florestal - um Estudo de Caso. Revista Agrogeoambiental, n. 2, p. 33-39, 2014. Disponível em: < http://dx.doi.org/10.18406/2316-1817v0n02014746 > doi: 10.18406/2316$1817 \mathrm{v} 0 \mathrm{n} 02014746$

GONÇALVES, D. S., SOUZA, P. A. de.; OLIVEIRA, A. L. de.; MARTIS, T. S. Diagnóstico ambiental e proposta de plano de recuperação da APP, fazenda Santa Juliana, Cariri do Tocantins- TO. Revista Núcleus, v. 13, n. 1, 2016. Disponível em: < http://dx.doi.org/ 10.3738/1982.2278.1562>. doi: 10.3738/1982.2278.1562.

INSTITUTO NACIONAL DE PESQUISAS ESPACIAIS (INPE). 2016. Disponível em: $<$ http://www.dgi.inpe.br/siteDgi/index_pt.php> Acesso em: 26 Jul. de 2016. 
LEOPOLD, L. B. et al. A producer for evaluating environmental impact. Washington, D.C.: U.S. Geol. Surv. Circ. U. S.G.C, 1971. 355 p.

MARTINS, S. V. Recuperação de áreas degradadas: ações em áreas de preservação permanente, voçorocas, taludes rodoviários e de mineração. 3. ed. Viçosa, MG: Aprenda Fácil Editora, 2013. v. 1. 264 p.

MARTINS, S. V. Recuperação de matas ciliares: no contexto do Novo Código Florestal. 3. ed. Viçosa, MG: Aprenda Fácil Editora, 2014. v. 1. 220p.

MARTINS, S. V. Restauração Ecológica de Ecossistemas Degradados. 2. Ed. Viçosa, MG: Editora UFV, 2015. v.1376 p.

NERY, C. V. M.; MOREIRA, A. A.; FERNANDES, F. H. S.; ALMEIDA, R. P. Uso do Sensoriamento Remoto na Detecção de Mudança na Microrregião de Montes Claros/MG. Revista Brasileira de Geografia Física, v.7, n. 1, p. 130 -145.

ODEBRECHT AMBIENTAL/SANEATINS. Informativo da qualidade da água ano XI- № 11. Disponível em: <http://www.odebrechtambiental.com/tocantins/wpcontent/uploads/sites/21/2015/10/RA_Wanderl\%C3\%A2ndia.pdf>. Acesso em 11 jun. de 2016.

OLIVEIRA, A. L. de.; SOUZA, P. A. de.; BENDITO, B. P. C.; GONÇALVES, D. S.; SANTOS, A. F. dos. Proposta de recuperação para a nascente do córrego mutuca em Gurupi - TO. Enciclopédia Biosfera, Goiânia, v. 11, n. 22, p. 2447-2465, 2015. Disponível em:<http://dx.doi.org/10.18677/Enciclopedia_Biosfera_2015_215_C>.doi: 10.18677/Enciclopedia_Biosfera_2015_215_C.

SÁNCHEZ, LE. Avaliação de impacto ambiental: conceitos e métodos. São Paulo: Oficina de Textos, 2006. 495p.

TOCANTINS. Constituição (2008). Lei no 1.939, de 24 de janeiro de 2008. Palmas, TO, 24 jan. 2008.

TOMMASI, LR. Estudo de Impacto Ambiental. São Paulo, 1993. 354 p. 